\title{
SpineCor treatment for adolescent idiopathic scoliosis - 5 years follow-up after weaning of the brace
} AB Circo*, C Coillard and CH Rivard

\author{
Address: Research Center, Sainte-Justine Hospital, \& University of Montreal, 3175 ch. Côte Ste-Catherine, Montréal, Québec, H3T 1C5, Canada \\ Email: AB Circo* - alin_circo@yahoo.ca \\ * Corresponding author
}

from 6th International Conference on Conservative Management of Spinal Deformities

Lyon, France. 21-23 May 2009

Published: I4 December 2009

Scoliosis 2009, 4(Suppl 2):O55 doi:I0.II86/I748-7|6I-4-S2-O55

This abstract is available from: http://www.scoliosisjournal.com/content/4/S2/O55

(c) 2009 Circo et al; licensee BioMed Central Ltd.

\section{Objective}

Knowing that any apparent correction of a scoliosis curve that occurs during rigid brace treatment for adolescent idiopathic scoliosis (AIS) can be expected to be lost over time, the purpose of this prospective interventional study was to evaluate the stability of the spine 5 years after the weaning point of the SpineCor brace.

\section{Study design}

From 1993 to 2009, 840 patients were treated for AIS using the SpineCor brace. 495 fitted patients had a definitive outcome, and 405 patients finished the treatment with the SpineCor brace. 94 patients had at least 5 years of follow-up. The assessment of brace effectiveness included the following: percentage of patients who had a $5^{\circ}$ or less curve progression and the percentage of patients who had $6^{\circ}$ or more progression; percentage of patients who have been recommended for or have undergone surgery before skeletal maturity; percentage of patients with curves exceeding $45^{\circ}$ at maturity (end of treatment); 2-years follow-up beyond maturity to determine the percentage of patients who subsequently underwent surgery; percentage of patients that corrected or stabilized their Cobb angle 5 years after the weaning point.

\section{Results}

Looking at the stability of the curves after the end of the treatment, $29 \%$ of the patients still continued their correction after the weaning point, 63.5\% remained stable, and only $7.5 \%$ progressed by more than $5^{\circ}(4.3 \%$ of them had a surgery recommendation after the weaning point).

\section{Conclusion}

The SpineCor brace is effective for the treatment of adolescent idiopathic scoliosis. Positive outcomes are maintained 5 years after the weaning of the brace. Moreover, one third of the patients still maintained correction of their Cobb angle in the five-year period after the end of the treatment. 